\title{
GEOMORFOLOGIA E SEDIMENTOLOGIA DA GELEIRA UNION, MONTANHAS ELLWORTH, ANTÁRTICA OCIDENTAL
}

\author{
Vanessa do Couto Silva Costa ${ }^{(a)}$, Rosemary Vieira $^{(\mathrm{b})}$ \\ (a) Departamento de Geografia/Instituto de Geociências, Universidade Federal Fluminense, vanessacosta@ id.uff.br \\ (b) Departamento de Geografia/Instituto de Geociências, Universidade Federal Fluminense, rosemaryvieira@id.uff.br
}

\section{Eixo: GEOCRONOLOGIA E ESTUDOS PALEOAMBIENTAIS}

\begin{abstract}
Resumo
As análises geomorfológicas e sedimentológicas são ferramentas importantes para a produção de dados por meio das formas glaciais e depósitos sedimentares, e, através destas o presente trabalho procura identificar evidências de mudanças climáticas e ambientais no manto de gelo da Antártica Ocidental. As atividades de campo foram realizadas na geleira Union, setor meridional das montanhas Ellsworth, Antártica Ocidental, durante a Expedição Criosfera no verão de 2011/2012. Os métodos empregados foram o sensoriamento remoto na identificação e mapeamento de depósitos e feições e coleta de dados e análise dos sedimentos coletados. Os dados apontam para a modificação da maioria dos sedimentos pela ação dos ventos constantes advindos do interior do continente, os sedimentos são modificados através do clima e associados a localização na geleira. Também foram identificadas feições que indicam abrasão por parte das geleiras, em microescala por estrias, e em macroescala através da feição stoss and lee as quais indicam o paleofluxo da geleira.
\end{abstract}

Palavras chave: Antártica; Paleoclimatologia; Geomorfologia Glacial; Sedimentologia.

\section{Introdução}

Entender as interações entre a Antártica e o clima é fundamental para a compreensão das mudanças climáticas e ambientais globais (SIEGERT e FLORINDO, 2008). O estudo do manto de gelo da Antártica Ocidental através da geomorfologia glacial contribui para o entendimento da história glacial e mudanças climáticas passadas associadas aos ciclos glaciais, auxiliando na calibração de modelos climáticos para previsões de mudanças climáticas e ambientais futuras e no entendimento dos processos que causam as flutuações no volume de gelo tais como a deglaciação acelerada, que influencia na elevação do nível médio do mar (CHEN et al., 2006). As dinâmicas ocorridas a partir do Último Máximo Glacial (20.000 18.000 anos AP) advindas das mudanças climáticas, transformaram a paisagem dos ambientes glaciais em todas as regiões. O interior da Antártica não foi tão investigado quanto suas regiões periféricas, por considerar que a deglaciação e o fluxo de gelo são relativamente lentos. Entretanto, parte do manto de gelo se encontra a aproximadamente 900m abaixo do nível do mar e em contato direto com o oceano, onde participa de trocas diretas de temperatura, embora não se tenha certeza da magnitude, a base do manto de gelo é vulnerável e muito suscetível a transformações a partir das mudanças de temperaturas marítimas (RIVERA et al., 2010; ROSS et al., 2014). 


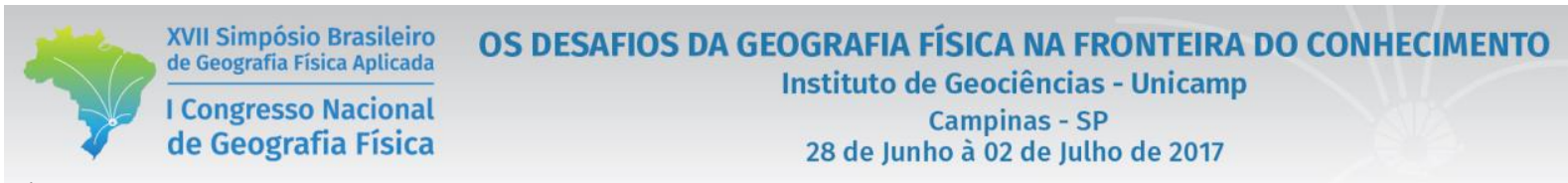

\section{2. Área de Estudo}

A região da Geleira Union, localizada nas montanhas Ellsworth, manto de gelo da Antártica Ocidental, (7946’S, 8324'W) (Erro! Fonte de referência não encontrada.) é uma das regiões sensíveis às mudanças e carecem de estudos mais detalhados quanto aos processos geomorfológicos localizados.

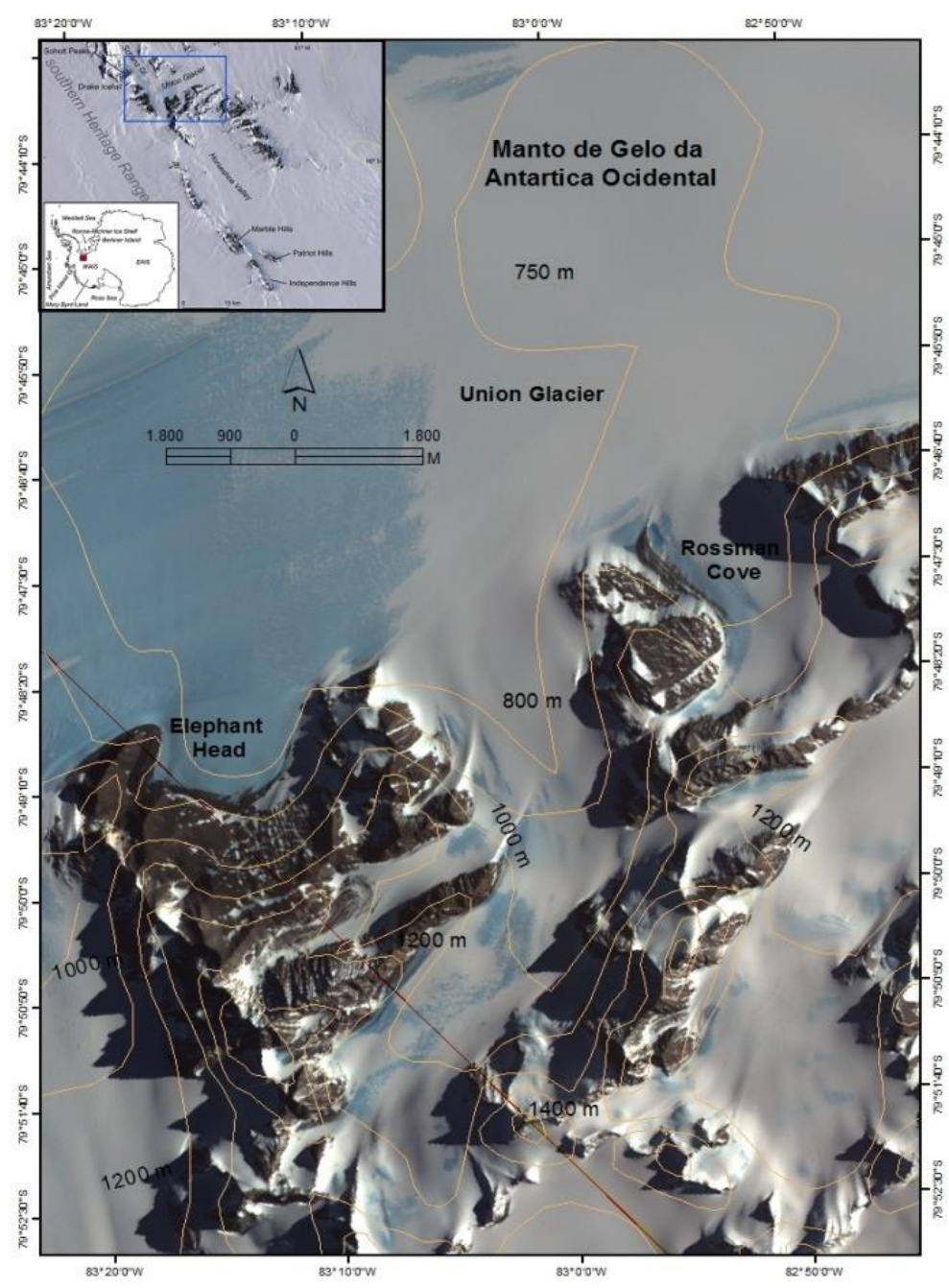

Figura 1 - Localização das regiões de estudo (Geleira Union, Elephant Head, Rossman Cove)

A região estudada contém evidências geomorfológicas e sedimentares associadas ao comportamento do manto de gelo e suas antigas retrações e expansões desde o Quaternário. Investigações geomorfológicas durante o Ellsworth Mountains Project (1979-1980) concluíram que os processos de deglaciação deixaram expostas feições erosivas e sedimentares. Marcas erosivas (trimline) mapeadas por Denton et al. (1992) nas montanhas Ellsworth, também sugeriram que nos últimos 15 mil anos o manto de gelo da Antártica Ocidental esteve 450 a 650 metros acima da superfície atual (DENTON et al., 1992). 
Em momentos de retração, houve exposições da topografia subglacial, também expondo feições deposicionais denominadas morainas, nas quais incluem as morainas de gelo azul (Erro! Fonte de referência não encontrada.), estas de origem subglacial são descobertas da neve após a ablação provocada pela erosão dos ventos. Estas feições são dadas de maior relevância para este trabalho, sua localização marca antigas margens de geleiras e podem explicar ciclos históricos de expansão e retração da geleira Union. As áreas de gelo azul, onde são localizadas as morainas de gelo azul, estão geralmente localizadas acima de uma topografia subglacial rugosa. Topografias irregulares emergidas na superfície, denominadas nunatacks, fazem parte também do relevo subglacial (VIEIRA e SIMÕES, 2011).

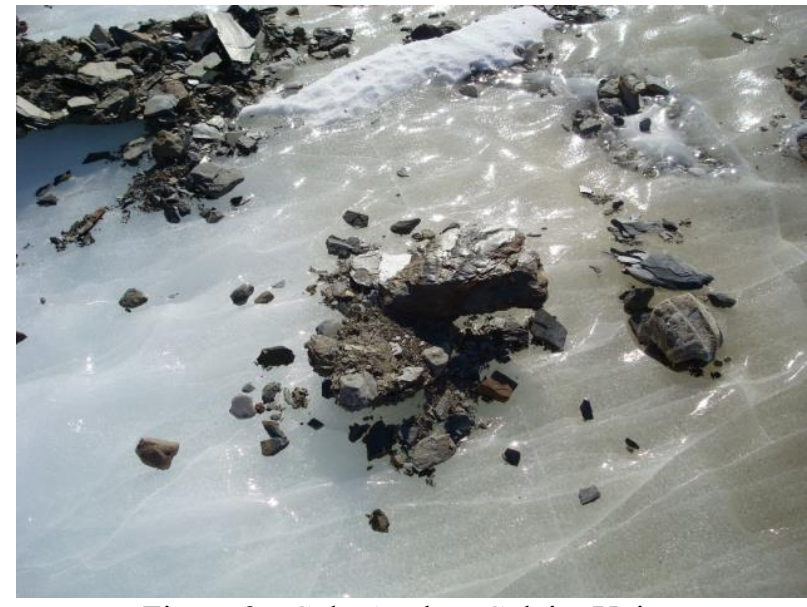

Figura 2 - Gelo Azul na Geleira Union

A geleira Union é classificada como geleira de base fria; em trabalhos antigos, sem evidências geológicas ou isotópicas, admitia-se que neste tipo de geleira não ocorre trabalho geomorfológico, pois entre sua base e o extrato rochoso há pouca água de degelo e com isso, não há deslizamento e abrasão. Entretanto, Cuffey et al. (2000) sugeriram suplantar esta convencional hipótese, comprovando a partir das técnicas de composição isotópica, processos basais de deslocamento e abrasão na geleira Meserve, Antártica, com temperatura média basal de $-17^{\circ} \mathrm{C}$, através da fusão seguida de recongelamento. Atkins et al. (2002) vai mais além, descrevendo a geomorfologia glacial produzida por processos de erosão e deposição da geleira de Allan Hills na Antártica, as feições mapeadas indicaram avanços e retrocessos da geleira, confirmando o trabalho geomorfológico da geleira de base fria na modificação da paisagem.

\section{Procedimentos Metodológicos}

Análises de formas glacialmente modificadas na geleira Union foram feitas a partir dos trabalhos de campo e materiais coletados durante a expedição Criosfera, realizada no verão de 2011-12. 
Foram realizadas observações e mensurações das feições erosivas e deposicionais, em especial, identificação e classificação de morainas. Imagens ASTER (2007), LANDSAT ETM (2010) e COSMO (2011) foram empregadas para a localização e identificação das áreas de amostragem e de feições.

Para a identificação e mapeamento das feições morfológicas mais marcantes foram usadas imagens do sensor ASTER (Advanced Spaceborne Thermal Emission and Reflection Radiometer - ano 2007), com resolução espacial de 15m, nas três bandas VNIR (visível e infravermelho-próximo). Foram introduzidos parâmetros de correção de projeção, sistema de coordenadas Polar Estereográfica e sistema geodésico de referência WGS84.

A sedimentologia e o mapeamento das feições são utilizados como meio para o entendimento dos processos glaciais geomorfológicos da região. Dados morfométricos foram obtidos das imagens com o uso do software ArcGis 10.1 para confecção de uma mapa geomorfológico.

As amostras sedimentares analisadas neste trabalho foram coletadas durante a expedição Criosfera nas seguintes áreas:

a) Geleira Union $-79^{\circ} 45.666^{\prime} \mathrm{S} / 83^{\circ} 15.895^{\prime} \mathrm{W}$;

b) Rossman Cove $-79^{\circ} 47.849^{\prime} \mathrm{S} / 82^{\circ} 53.536^{\prime} \mathrm{W}$;

c) Elephant Head $-79^{\circ} 49.298^{\prime} \mathrm{S} / 8^{\circ} 20.426^{\prime} \mathrm{W}$;

As amostras foram coletadas com uma pá, em pequenas cavidades, a fim de evitar o material meteorizado da superfície, na quantidade de 100 gramas e postas em sacos plásticos, contendo o código de cada amostra. Em cada local de coleta foram realizados pontos de controle de GPS (altitude e coordenadas, com margem de erro de 3 metros), fotografia com escala e observação do ambiente de entorno (orientação, tamanho do depósito, matriz). Também foram coletados 50 clastos por amostra, com eixo maior $>15 \mathrm{~mm}$ para análise morfométrica.

A distribuição do tamanho das partículas de cada amostra foi determinada em laboratório por peneiramento a seco com intervalos em phi, de $-3 \varnothing$ a $4 \varnothing(8 \mathrm{~mm}$ a $0,063 \mathrm{~mm})$. A análise da forma dos clastos (arredondamento) e a descrição das características superficiais (estrias e polimentos) foram feitas em lupa binocular a fim de analisar as fácies dos depósitos. 50 clastos de cada amostra foram mensurados manualmente usando caliper digital para determinar visualmente o tamanho relativo dos três eixos ortogonais: $a$ (maior), $b$ (intermediário) e $c$ (menor).

Os valores de arredondamento dos clastos (de 2 a $8 \mathrm{~mm}$ ) foram assignados usando o critério descritivo de Benn e Ballantine (1994), modificado de Powers (1953). Em adição, a análise de co-variância do índice 


\section{OS DESAFIOS DA GEOGRAFIA FÍSICA NA FRONTEIRA DO CONHECIMENTO \\ Instituto de Geociências - Unicamp \\ Campinas - SP \\ 28 de Junho à 02 de Julho de 2017}

$\mathrm{C}_{40}$ (\% de clastos com eixo $\left.c / a=0,4\right)$ e índice RA (\% de clastos muito angulosos e angulosos) foi conduzida de acordo com o método proposto por Benn e Balllantyne (1994) e Evans e Benn (2004).

Clastos que apresentam feições de placas ou bastão são mais prováveis de ter valores $\mathrm{C}_{40} \leq 0.4$ do que os clastos que apresentam feições cúbicas (ADAM e KNIGHT, 2003). Esse método distingue os sedimentos que foram transportados ativamente daqueles que o foram de forma passiva pela geleira (BENN e BALLANTYNE, 1994; BENNETT et al., 1997).

Diagramas ternários e histogramas, produzidos através do software Triplot, apresentam a forma e o arredondamento dos clastos coletados.

\section{Resultados e Discussões}

\subsection{Feições Geomorfológicas}

Foram identificadas feições periglaciais bem preservadas, incluindo morainas com núcleo de gelo e feições erosivas em mesoescala e microescala (estrias e feições stoss and lee gigantes - Figs. 3a e 3b). Por meio da interpretação visual de imagens ASTER e atividades de campo, foi confeccionado um mapa geomorfológico e glaciológico (Fig. 4).

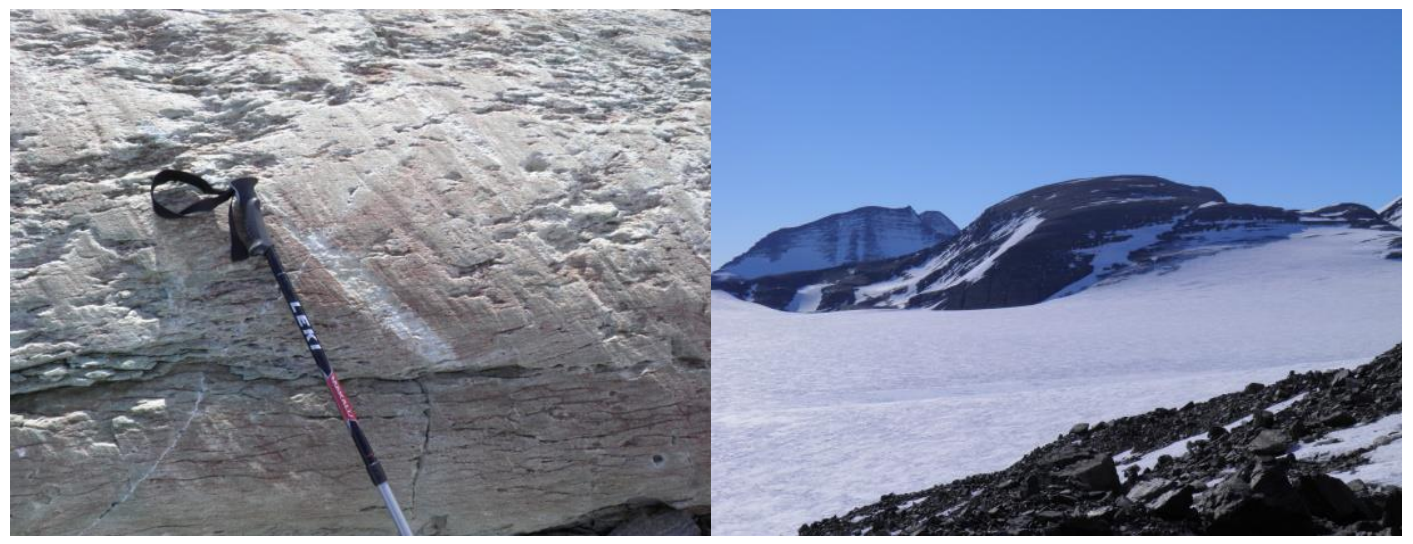

Figura 3 - a) Estrias em Rossman Cove. b) Stoss and lee gigante. 

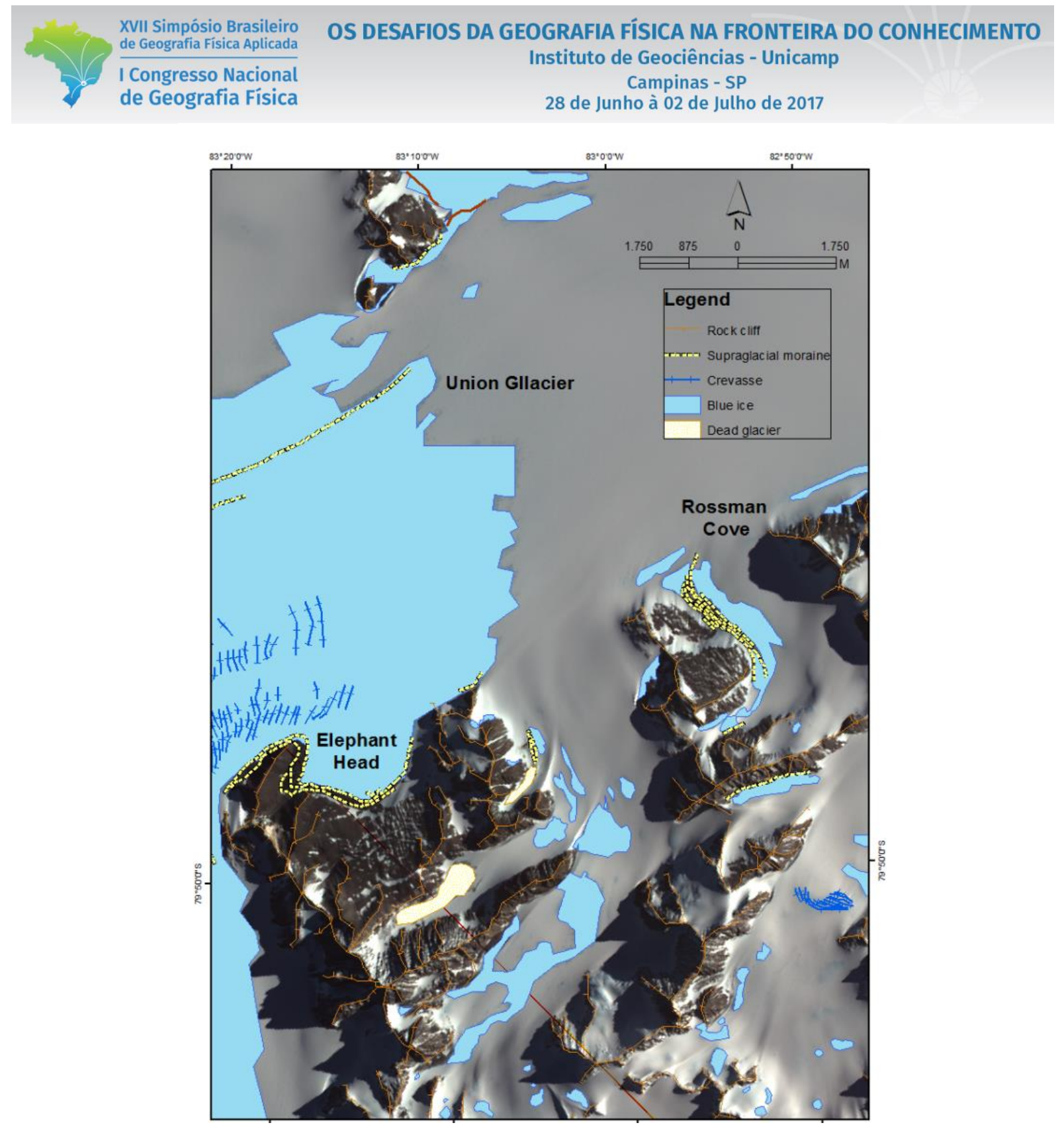

Figura 4 - Mapa geomorfológico da área de estudo

Duas feições erosionais nas áreas livre de gelo ao norte da região de Rossman Cove se destacam por revelar a abrasão por parte das geleiras em diferentes períodos, foram identificados sulcos e estrias bem definidas. Algumas das estrias apresentam uma coloração mais clara que a rocha original, apresentando sinais visíveis de oxidação. As estrias mais claras podem ter sido produzidas por atividade glaciais mais recentes. As feições estão situadas em uma região entre 40-50 metros acima da superfície de gelo atual.

A feição de stoss and lee gigante entalhada na rocha de origem é a maior feição erosiva que representa a ação e direção do gelo na topografia local. A montante do fluxo de gelo apresenta uma superfície suave e uniforme, enquanto a jusante a superfície da rocha se apresenta triturada e descontínua e o topo da 
superfície do afloramento se apresenta muito intemperizado. Os stoss and lee podem indicar um período passado em que a camada de gelo cobria parte topografia exposta da área estando aproximadamente 200 metros acima da superfície atual.

Sucessivos cordões morâinicos, representando feições deposicionais foram encontrados em Rossman Cove, no Vale Elephant Head e na geleira Union. Exceto em Elephant Head, todas as formações morâinicas se desenvolvem em áreas de gelo azul com conteúdo de gelo abaixo dos detritos.

Cordões de morainas laterais emergem no manto de gelo a nordeste da região de Rossman Cove, na área central da geleira Union e no Vale Elephant Head seguindo ao sul pela margem da geleira Union (Fig. 5). Em Rossman Cove, as cristas morâinicas arqueadas demostram ser contínuas para a direção nordeste em cordões estreitos, representando distintas escalas temporais, sendo o cordão mais externo o mais antigo.

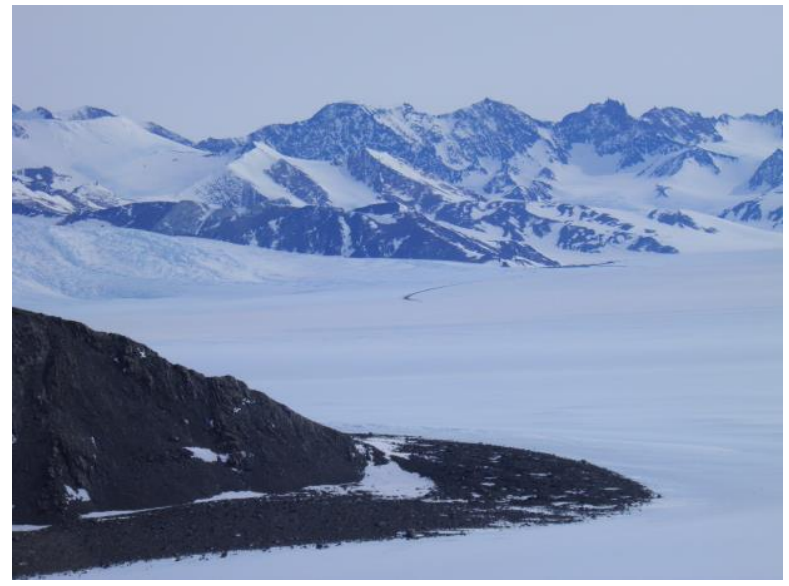

Figura 5 - Morainas supraglaciais na entrada do Vale Elephant Head

Extensos cordões elevados de morainas com núcleo de gelo alcançam até 7 metros de altura com predominância de cascalhos e seixos, se desenvolveram no flanco marginal da geleira Union, e diante o Vale Elephant Head afinando no decorrer do interior do vale, que pode ser explicado pela direção do fluxo glacial em direção ao limite do vale, por processos periglaciais com atividades nas vertentes ou pela presença de uma superfície do manto de gelo mais elevada.

Na região central da geleira Union se desenvolve uma cadeia morâinica de aproximadamente 2,35 Km, mas com alturas que não excedem $1 \mathrm{~m}$. Em sua composição mal selecionada predomina-se de areias e seixos até cascalhos.

A origem destas morainas implicam diferentes processos, porém as áreas de gelo azul definem condições ambientais inerentes, onde a predominância de ventos catabáticos oriundos do platô polar provocam a 
sublimação da neve superficial e processos erosivos que demarcam características passadas do manto de gelo.

\subsection{Granulometria e Morfometria}

As análises das amostras de sedimentos localizados na geleira Union indicam quase $100 \%$ de cascalho arenoso e areia, cascalho fino compreende $68 \%$ a $93 \%$ dos sedimentos. O conteúdo de silte não supera $3,1 \%$ da amostra, podendo ser justificado a predominância de cascalho por ser uma região sujeita a ação dos fortes ventos catabáticos.

Os diagramas ternários e de Zingg indicam que a forma dos clastos é variada, porém com predomínio de placas. Os histogramas apresentam assimetria negativa, com exceção de uma amostra, indicando uma baixa proporção de clastos angulosos e muito angulosos. Predominam-se clastos subarredondados e subangulosos. Esta facie pode ser interpretada como till basal com incorporação de sedimentos previamente meteorizados pertencentes a geleiras já cobertas pelo manto de gelo. A justificativa dos elevados percentuais de clastos arredondados podem se dar as modificações pela abrasão do vento.

As amostras das morainas supraglaciais região de Rossman Cove também predominaram o cascalho (79\% cascalho, $21 \%$ areia), com material fino escasso (média de $0,1 \%$ de silte) pois a região também está sujeita aos ventos catabáticos. Os depósitos de Rossman Cove se destacam pela grande cobertura superficial de material mal selecionado com cascalhos e matacões meteorizados de rocha in situ.

Os diagramas ternários indicaram o predomínio de clastos com índice $\mathrm{C}_{40} \leq 0,4$, indicando o predomínio de placas e lâminas, confirmado também a partir do diagrama de Zingg. Os histogramas apresentaram uma assimetria negativa indicando a menor proporção de clastos angulosos e muito angulosos; os clastos são predominantemente subarredondados e subangulosos. Foram identificados clastos com micro-estrias. Está facie pode ser interpretada como till basal também com incorporação de incorporando material previamente meteorizado e sedimento glaciogênico meteorizado derivado das geleiras posteriormente cobertas pelo manto de gelo. Os sucessivos cordões apontam para as posições em um processo de recuo da geleira, que proporcionaram a deposição do material. Modificações posteriores pela abrasão do vento e o maior transporte do material de granulometria mais fina nesta área podem explicar os percentuais elevados de clastos arredondados na superfície.

A análise granulométrica no vale Elephant Head evidencia o predomínio de cascalho arenoso e areia. No entanto, é o sítio onde os percentuais são menores, compreendendo de 47 a $70 \%$ dos sedimentos. O conteúdo de areia varia de 40 a 52\%. O vale é mais protegido e há aporte de material de vertentes, o que 


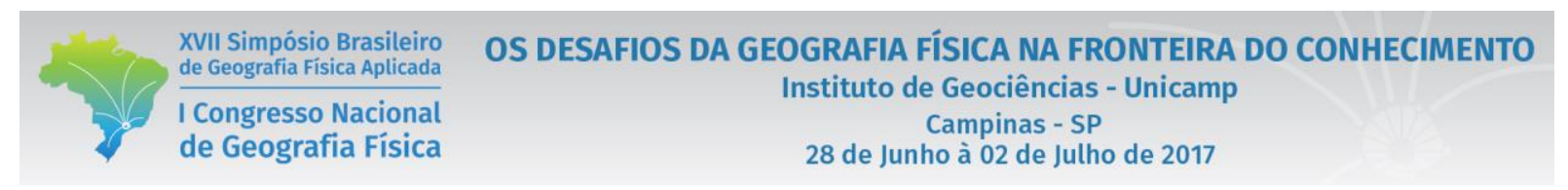

pode justificar a maior presença de areias e a má seleção dos sedimentos. Todas as amostras apresentam assimetria positiva.

A moraina supraglacial do vale Elephant Head, junto à área de gelo azul foi o local com menos amostras coletadas, devido à dificuldade de coleta em meio a grande concentração de matacões e ao gelo subsuperficial massivo. Das amostras coletadas o percentual de cascalho arenoso é superior aos $80 \%$ entre os sedimentos, seguido de areias (entre 10 e 13\%). A participação de material fino é muito pouco representativo, sendo localizada junto à área de gelo azul observa-se que a ação do vento é intensa.

Ao correlacionar os dados de assimetria com o grau de seleção de todas as amostras (Fig. 6), foi constatado o predomínio da granulometria grossa nos sedimentos, com presença pouco representativa de sedimentos finos. Essa característica é evidente na assimetria positiva na maioria das amostras e no grau de seleção entre 0 e 2 . A partir de 2 as amostras tendem a mostrar-se muito mal selecionadas. Os depósitos morâinicos concentram classes texturais cascalhosa, típicos de material morâinico. A exceção coube às amostras coletadas ao longo da moraina central da geleira Union, o que pode ser explicada por duas condições: (1) a altura do cinturão morâinico da geleira Union possui no máximo 1 metro de altura, contrastando com os cinturões de Rossman Cove e das morainas supraglaciais de Elephant Head, que alcançam em alguns pontos a 5 metros. (2) Grande parte dos sedimentos na moraina da geleira Union ainda estão juntos à superfície do gelo. Aliada a essa condição está a forte ação dos ventos locais sobre cordões morâinicos mais elevados, transportando os detritos mais finos (fração areia).

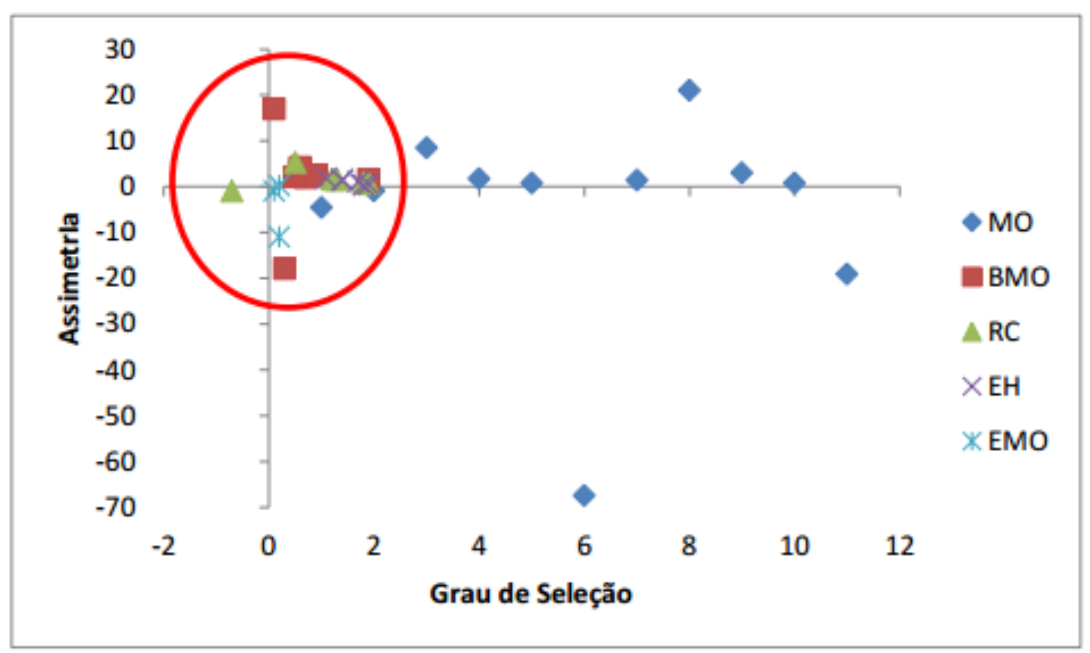

Figura 6 - Gráfico de dispersão das varíaveis relacionados ao tamanho dos sedimentos: assimetria e grau de seleção (MO - Morainas da geleira Union; BMO - Morainas de Rosman Cove; RC - Rosman Cove; EH - Elephant Head; EMO - Morainas de Elephant Head). 


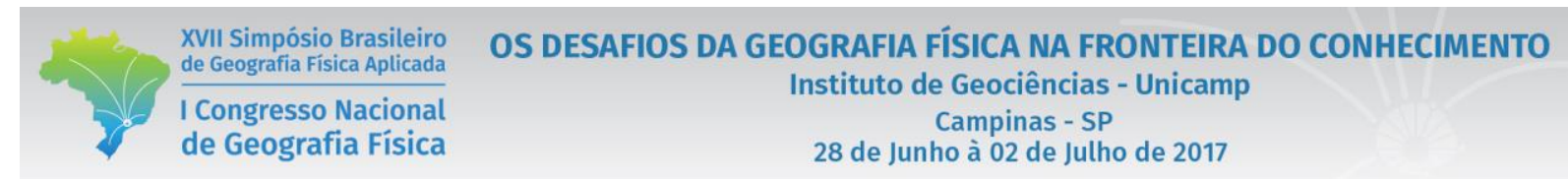

O gráfico representado na Figura 7, conhecido como diagrama de co-variância, analisa como dois aspectos dos clastos (forma e arredondamento) podem variar com a procedência e a história do transporte dos depósitos glaciais (EVANS e BENN, 2004). Segundo a classificação de localização de áreas de controle sobre os sedimentos (supraglacial, subglacial e fluvial) de Luka et al. (2013), as amostras sedimentares da região da geleira Union se encontram no grupo de áreas de alta montanha, com aporte supraglacial, representados pelos valores elevados de RA e baixos de RWR.

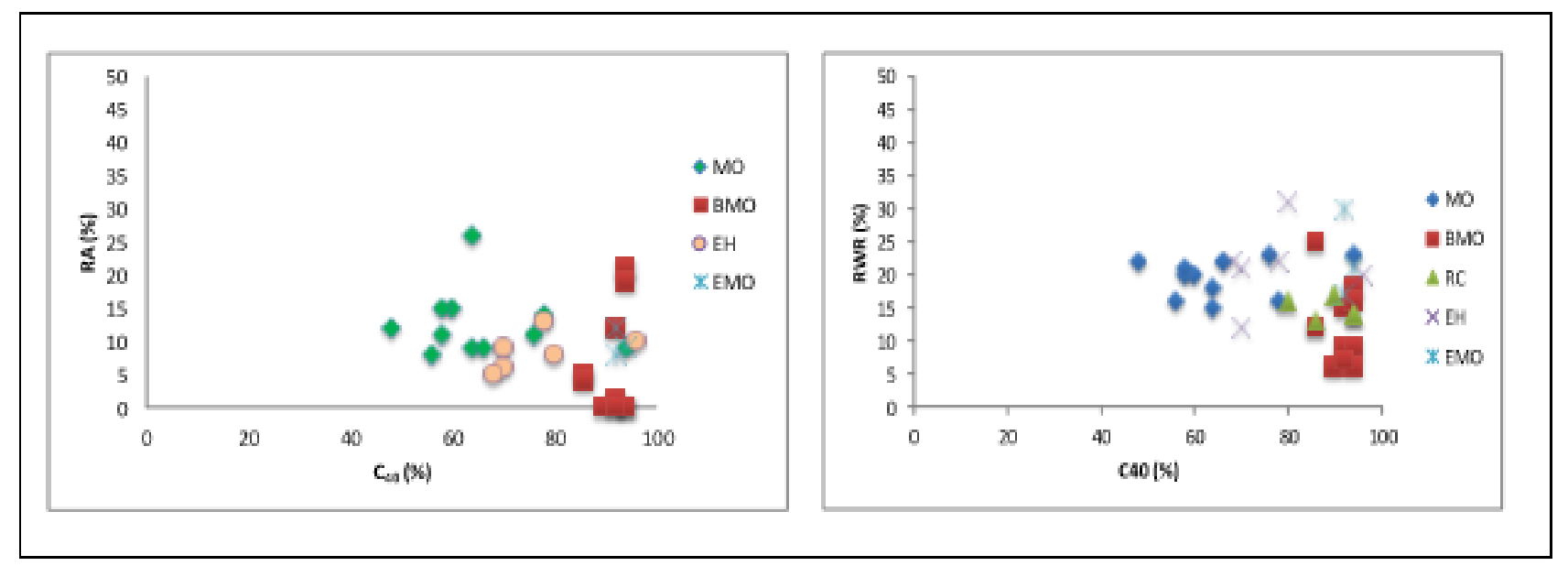

Figura 7 - Gráfico de co-variância com todas as amostras analisadas: C40 (\% de clastos com raio axial c/a $\leq 0.4)$ contra RA (\% de clastos muito angulares e angulares) e RWR (\% de clastos arredondados e bem arredondados) dos sítios analisados. Cada símbolo representa uma amostra com 50 clastos. (MO) geleira Union; BMO -Morainas

Rossman Cove; RC - Rossman Cove Hill); EH - Vale Elephant Head; EMO (Morainas Elephant Head).

\section{Considerações Finais}

As feições erosivas e deposicionais, tais como os cordões morâinicos e depósitos supraglaciais identificadas fizeram parte dos processos de deglaciação que modificaram o tamanho e a espessura do manto de gelo da Antártica Ocidental, na área da geleira Union, em períodos passados. Morainas supraglaciais inferem antigos fluxos das geleiras, quando estas com maior volume, depositaram espessos depósitos em suas zonas marginais. Estas feições ainda foram afetadas pela ação constante dos ventos catabáticos advindos do interior do continente e podem ter sofrido processos de retrabalhamento do material detrítico por intemperismo. Neste trabalho foram identificadas algumas feições que identificam abrasão por parte das geleiras, tanto em microescala através de estrias quanto em macroescala pela feição stoss and lee, as quais adicionalmente indicam a direção de paleo fluxo da geleira. Porém, não foram encontradas provas suficientes de materiais transportados pela geleira subglacialmente. Em adição, o trabalho mostra, ainda de forma elementar, a importância da análise sedimentológica na reconstrução de antigos processos e ambientes 
Análises futuras de datação radiométrica, da composição química e mineralógica dos sedimentos e da direção do fluxo das geleiras são importantes para identificar a procedência do material e afirmar se houve ou não a participação de material subglacial, além do papel de diferentes litologias sobre a forma dos clastos.

\section{Agradecimentos}

A expedição Deserto de Cristal (2011/2012) foi financiada pelo CNPq e pelo Programa Antártico Brasileiro (PROANTAR). A Antartic Logistics \& Expeditions deu apoio desde o transporte aéreo até o apoio logístico em terra. A Fundação de Amparo à Pesquisa do Estado do Rio de Janeiro (FAPERJ) deu suporte à pesquisa através de equipamentos de laboratório e bolsas para alunos de iniciação científica. As imagens ASTER foram oferecidas por Jorge Arigony Neto (UFRGS) e processadas no Centro Polar e Climático (UFRGS). As análises dos sedimentos foram concluídas graças ao apoio das alunas Thairiny Fonseca e Livia Aguiar.

\section{Bibliografia}

ADAM, W.G.; KNIGHT, P.G. Identification of basal layer debris in ice-marginal moraines, Russell Glacier, West Greenland. Quaternary Science Reviews, 22 (14), p. 1407-1414, 2003.

ATKINS, C.B.; BARRETT, P.J.; HICOCK, S.R. Cold glaciers erode and deposit:evidence from Allan Hills, Antarctica. Geology, 30 (7), p. 659-662, 2002.

BENN D.I.; BALLANTYNE C.K. Reconstructing the transport history of glaciogenic sediments - a new approach based on the covariance of clast form indices. Sedimentary Geology, 91(1-4), p. 215-227. 1994.

BENNETT, M.R.; HAMBREY, M.J.; HUDDART, D. Modification of clast shape in high Arctic environments. Journal of Sedimentary Research 67 (3), p. 550-59, 1997.

CHEN, J.L.; WILSON, C.R.; BLANKENSHIP, D.D.; TAPLEY, B.D. Antarctic mass rates from GRACE. Geophysical Research Letters, Washington, DC, v. 33, 2006.

CUFFEY, K.M., CONWAY, H., GADES, A.M., HALLET, B., LORRAIN, R., SEVERINGHAUS, J.P., STEIG, E.J., VAUGHN, B., AND WHITE, J.W.C. Entrainment at cold glacier bed. Geology, v. 28, p. 351-354, 2000.

DENTON, G.H.; BOCKHEIM, J.G.; RUTFORD, R.H.; ANDERSEN, B.G. Glacial history of the Ellsworth Mountains, West Antarctic, in Webers, G.F., Craddock, C. e Splettstoesser, J.F. (eds), Geology and Paleontology of the Ellsworth Mountains, West Antarctic: Boulder, Colorado, Geological Society of America, Memoir 170, 403432.1992.

EVANS, D.J.A.; BENN, D.I. Facies description and the logging of sedimentary exposures. In: Evans, D.J.A. and Benn, D.I. (Eds.). A Practical Guide to the Study of Glacial Sediments. Arnold, p. 11-51, 2004.

FLORINDO, F.; SIEGERT, F. (Ed.). Antarctic climate evolution. Vol. 8.(3-11).Elsevier, 2008.

POWERS, M. C. A new roundness scale for sedimentary particles. Journal of Sedimentary Research, v. 23, n. 2 , 1953.

RIVERA, A.; Zamora, R.; RADA, C.; WALTON, J.; PROCTOR, S. Glaciological investigations on Union Glacier, Ellsworth Mountains, West Antarctica. Annals of Glaciology, 51(55), 91-96. 2010. 


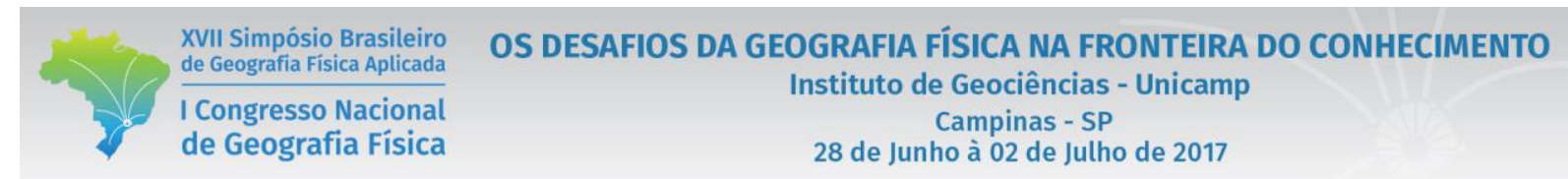

ROSS, N.; JORDAN, T. A.; BINGHAM, R. G.; CORR, H. F.J.; FERRACCIOLI, F.; BROCQ A.; RIPPIN, ANDREW, P.; SIEGERT, W. M. J. The Ellsworth subglacial highlands: inception and retreat of the West Antarctic Ice Sheet. Geological Society of America Bulletin, 126(1-2), 3-15. 2014.

VIEIRA, R., SIMÕES, J.C., Geomorfologia Glacial dos Montes Patriot e Independence, Montanhas Ellsworth, Manto de Gelo da Antártica Ocidental. Revista Brasileira de Geomorfologia, 12, p. 45-58, 2011. 